\title{
Creation of modern urban space of typical private-home districts
}

\author{
Yana Prelovskaya ${ }^{1, *}$ \\ ${ }^{1}$ Moscow State University of Civil Engineering, Yaroslavskoeshosse, 26, Moscow, 129337, Russia
}

\begin{abstract}
The main task of this article is to coverage a problem of reorganization of public areas located in private-home districts in cities of the middle Volga region. The study identified the main types of public spaces and the proposed strategy for the reorganization of common areas in the global experience an example. For today the territories built up by private houses are the most undeveloped parts of cities. This problem of urban development is especially important in regions of Russia. the survey revealed a lack of elaboration of planning documentation in this area, including frequent violated rules to ensure events for people with limited mobility, in terms of pedestrian and transport infrastructure.
\end{abstract}

\section{Introduction}

Formation of modern urban space. Methodology of reorganization of typical private-home districts, for example, in cities of the middle Volga region. Identifying the extent of development of this kind in the settlement system, study of moral and physical deterioration, determination of the share of public spaces, transport and pedestrian links, defining the vector of development. The main problems of these districts, analysis of global experience in this field. Proposal for reorganization of the street on the example of Ulyanovsk.

\section{City overview}

The author has chosen for this survey and an architecture review the cities of the central part of Russia near the Volga River: Kazan, Samara, Nizhny Novgorod and Ulyanovsk (Figure1).

*Corresponding author: ya-prel@yandex.ru 


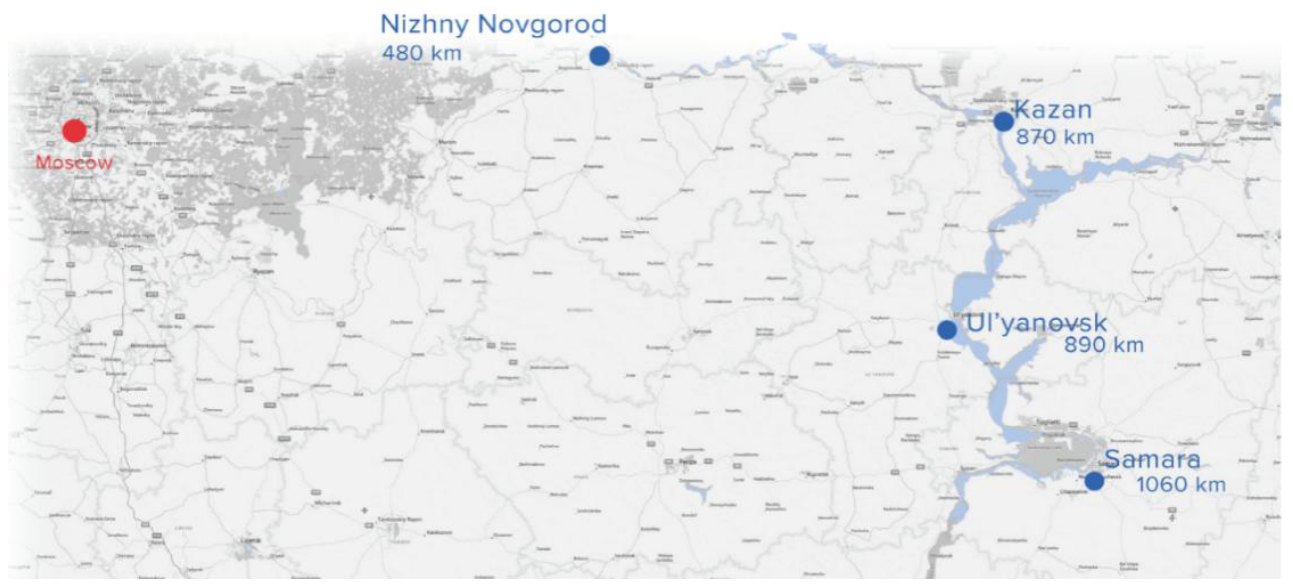

Fig.1. Region of the survey. Middle Volga region.

This report aims to pay attention to typical private-home districts situated mainly in central part of the cities. Unlike the modern multistory buildings, these are private-home districts that create an impression about a towns and its historically true spirit.

In the history of mankind, building of a private place for living was the first step for a man to get constructing skills. Today-individual living house formed urban area and subsequently towns and agglomerations. Look at amount of buildings of this type, located in the oldest part of towns. For example, the central part of Nizhny Novgorod consists of private houses for almost 30\% (Figure 2)[1]:

\section{NIZHNY NOVGOROD}

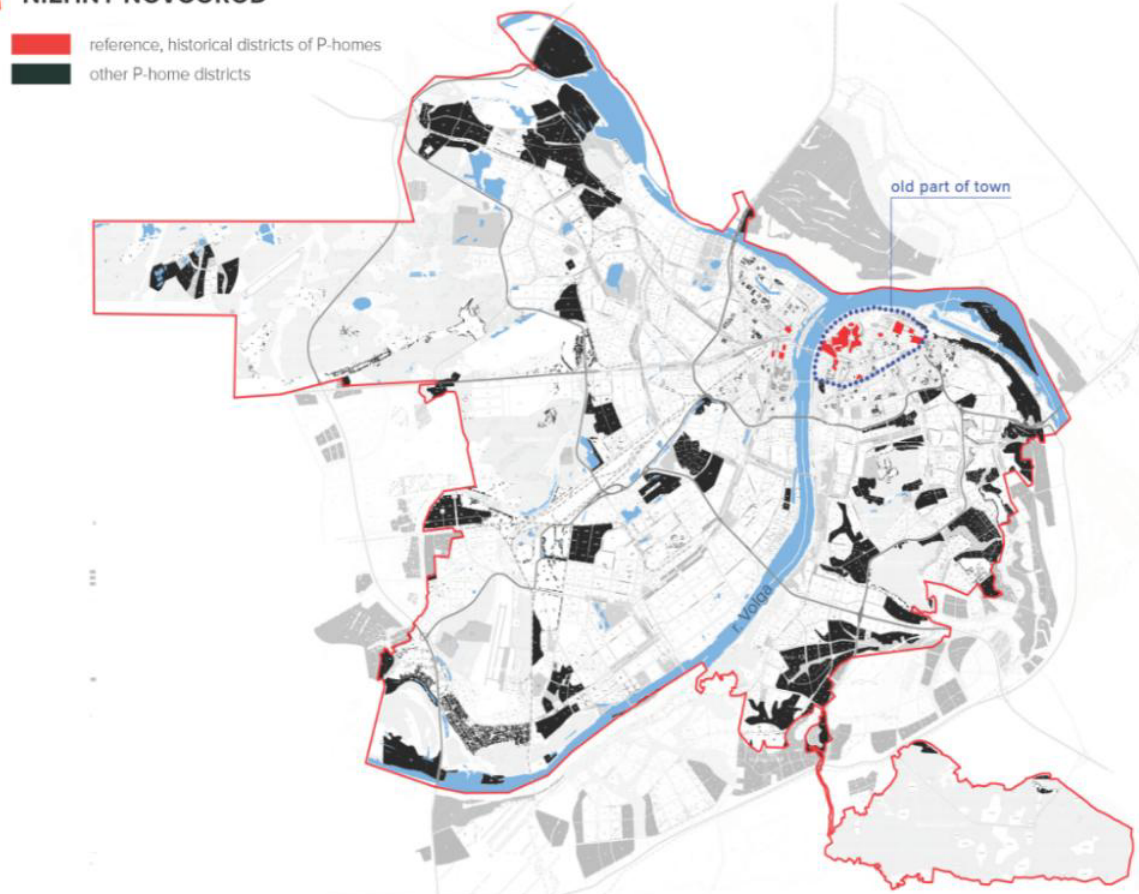

Fig.2.Areas of construction type private houses in Nizhny Novgorod. 
The situation in Kazan is similar to that in Nizhny Novgorod, i.e. there are areas of private houses both in the central historical part and throughout the whole territory of the city (Figure 3) [1]:

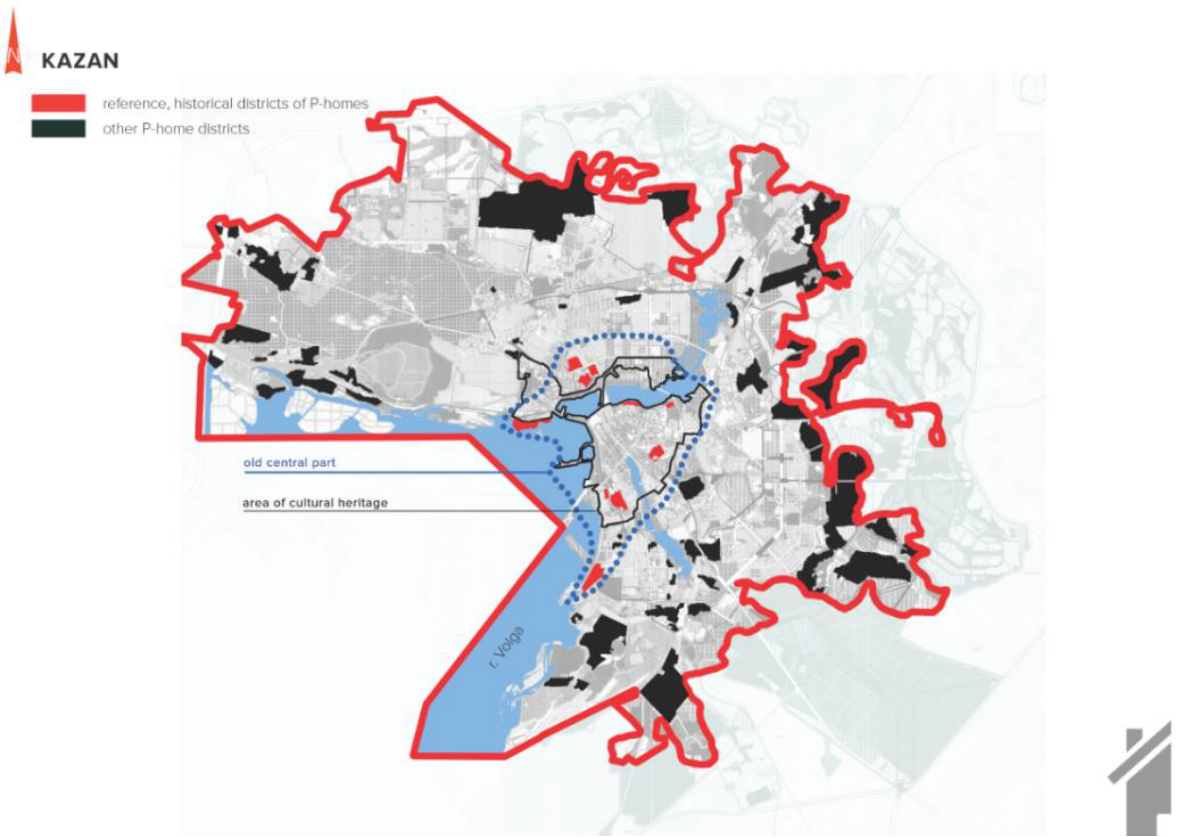

Fig.3.Areas of construction type private houses in Kazan.

In Samara, there are many historical mansions of rich merchants in the central partofthe city. Since the main activity of merchants was trade at the port, they were mostly located in a part area, close to the Volga(Figure 4)[1,2].

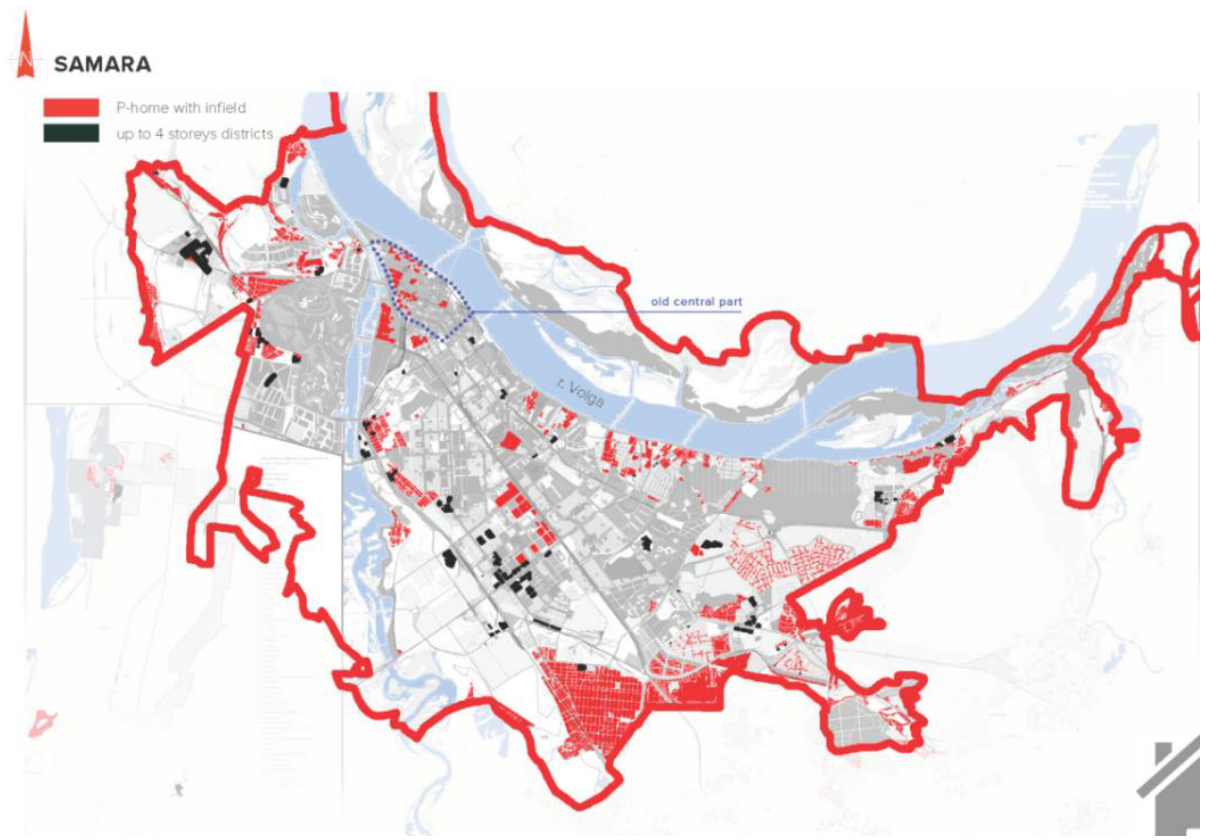

Fig.4.Areas of construction type private houses in Samara. 
Ulyanovsknear 100 years ago was - Simbirsk governorate. Pre-revolutionary Simbirsk was rightly called "noble" city. Today only old part of the center makes this imagination [3](Figure 5).

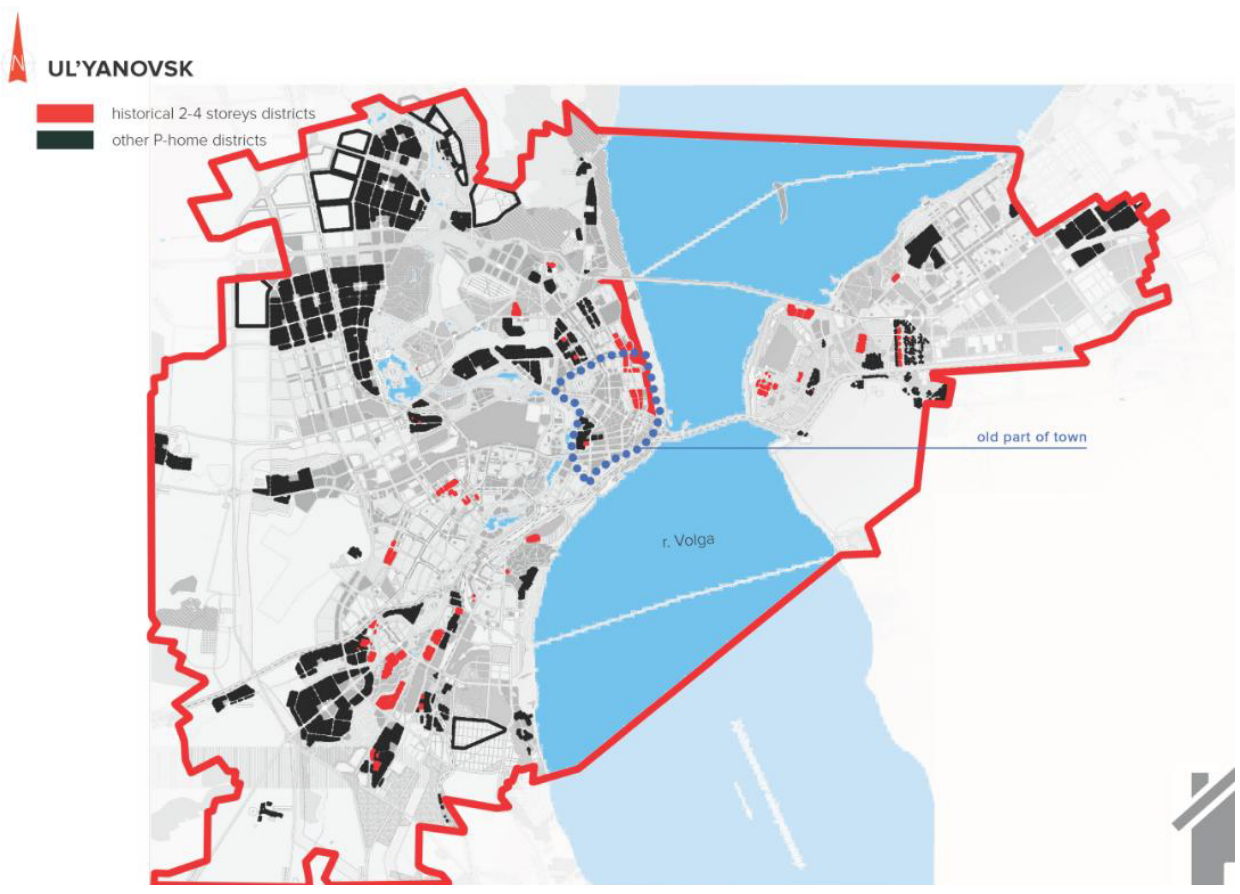

Fig.5.Areas of construction type private houses in Ulyanovsk.

Nowadays all the cities look modern and similar, but if one would walk around the center, in the old town and its historical heart, he could be lucky to find districts with prerevolution buildings.

\section{Results of overview}

In these countries private-home districts don't have strict standards.

As a rule, these areas have (Figure 6):

1) low-rise buildings;

2) disorderly system of streets and roads (as a result risk of accidents increases, there appears illegal business activities without any ecological standards, haven't socioeconomic pedestrian connections);

3) engineer communication across the streets and pedestrian paths(and as a result an increased risk of accidents);

4) parcels are irregularly formed;

5) lack of public space [4]. 


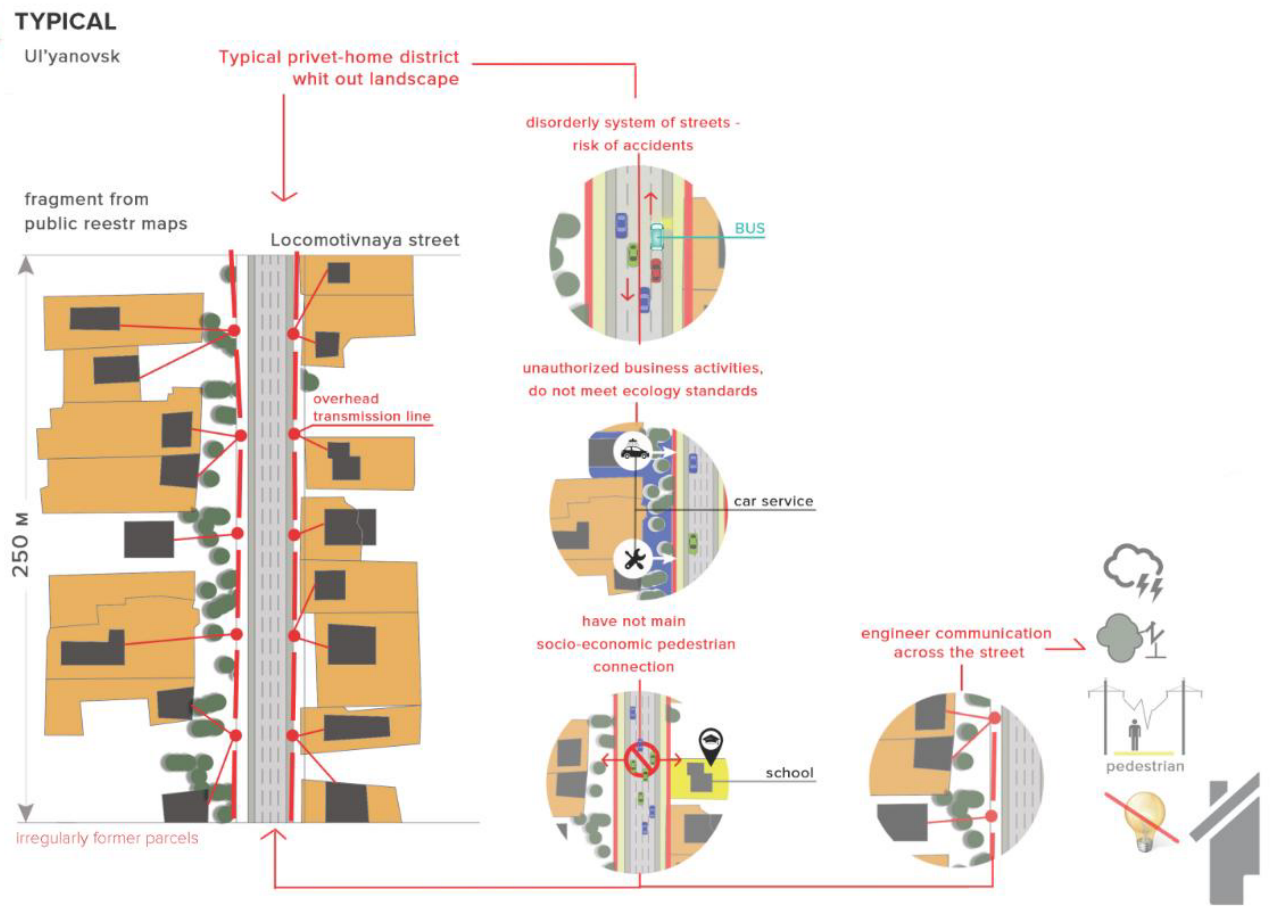

Fig.6. Main problems of private home districts in Russia (on the example of Locomotivnayastreetin Ulyanovsk).

A combination of all these factors results in formation of depressive urban and social areas. It is a common case, when a house in a poor condition is demolished instead of being repaired. Thus someone hog's territory for a new multi-story house or business center near a private house with a garden. The same urban planning decision as a rule doomed to extinction of the whole district, and what about other buildings near them - it does not matter. In case when a different approach would be applied to the territory, for example, an athletic school could be built. It will be useful to apply this space after training time - for fitness and work out (in order to attract investors); as a result the district would develop steadily (Figure 7)[5,6]. 


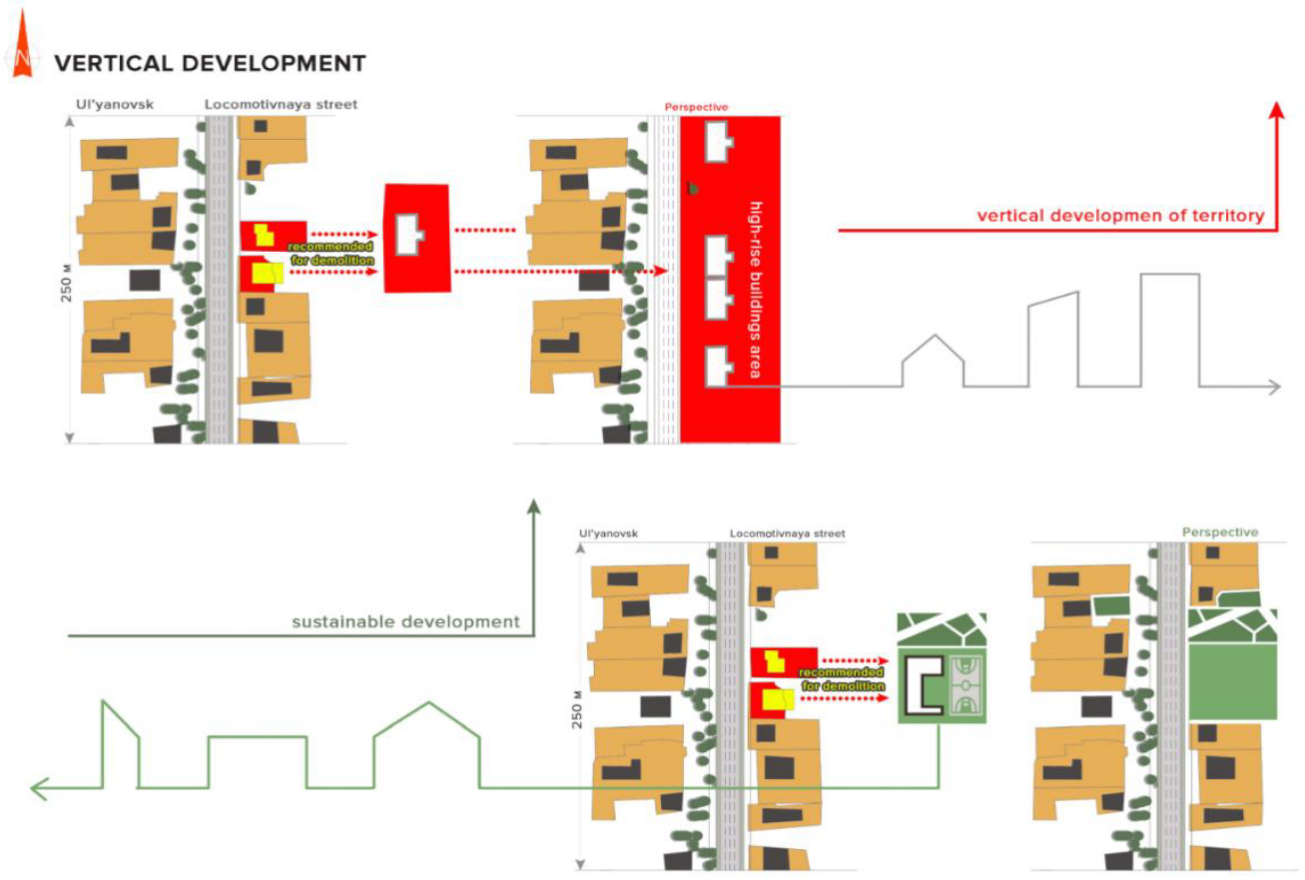

Fig.7.Vector of vertical development (Ulyanovsk, Locomotivnayastreet).

\section{International experience}

The global international experience in this aspect shows, that these districts are very common in the following regions.

China (Hong Kong): Though it is difficult to find place for all people, private-home districts are quite common. The road network is not so wide, but well developed, with lane for public transport and pedestrian connection. There are a lot of parking places for residents and guests. Hamburg (Germany): fencing function changed from green fence; all districts have public spaces, with modern urban open space for residents.

Austria: First of all, we can see functional division of territory depending on the type of districts, and the main entrance focused on the street, engineering communications conducted under the ground or changed on alternative energy sources.

Nebraska (USA): only15 or 20 years ago when these districts were former the main urban decision was applied, this location is not so popular in USA however we can see developed pedestrian connection, without engineering communication, public space and green areas for living, rigid streets organization, parking place for residents' and guests' cars [7]. It is worth mentioning, that the main difference of typical district in Russia and in the rest world - there are:

1) functional division of territory from type of area;

2) the rigid lines of urban planning;

3) developed pedestrian infrastructure;

4) buildings construction \& materials are same;

5) entrance group focused on the main road and pedestrian;

6) fencing is not so high like in our country, or nothing. This function changed from green fence;

7) engineering communications conducted under the ground; 


\section{Experimental section}

As a final we can use this terms in Ulyanovsk, Locomotivnaya Street (Figure 8): First of all we can find place for improve, than difference fences should change to green fence or nothing. Will define technical area for re-laying engineering communication under the ground - as a result we have more territory for pedestrian and special bus line.

Pedestrian structure will orient on the main entrance group for front of view. This structure gives areas for landscape and public places, which will connect whit social and infrastructure objects $[8,9]$.

\section{LANDSCAPE}
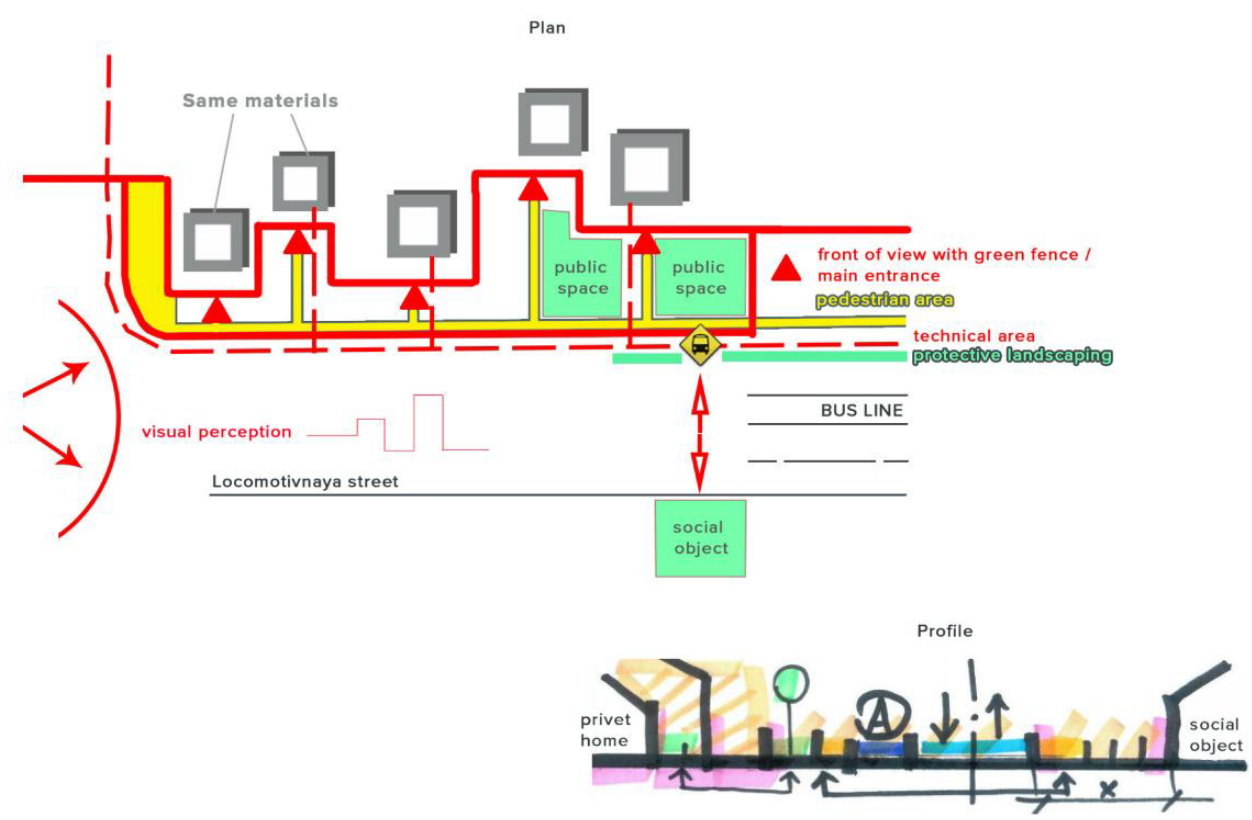

Fig.8.Proposal for reorganization Locomotivnaya Street (Ulyanovsk).

\section{Conclusions}

There are some cities where can't avoid so to stay vertical development and centralization. But in Russia, country who shave rich free landscape in the central regions.

We still can try to save stable, comparable to human-size and historically true environment. Guided by international experience in this matter, it seems possible to transform the areas of private houses of historical centers of cities to a modern comfortable living space.

\section{References}

1. https://tilemill-project.github.io/tilemill/

2. Guide to Modern Architecture (Moscow, 2006)

3. The Simbirsk book (Ulyanovsk-Simbirsk encyclopedia,Ulyanovsk,2004) 
4. Theories, methods and strategies for sustainable landscape planning. Landscape research to landscape planning: Aspects of integration, education and application (Springer, Dordrecht, 2006)

5. N.A.Samoylova, Vestnik MGSU, 11 (2013)

6. S.V.Kolobova, Proceedings of the Int. conf., 32(2013)

7. D. Geneletti, Landscape and Urban Planning, 1(2017)

8. Russian Federal law of 29.12.2004 No. 190-FZ

9. Russian Federal law of 25.10.2001 No. 136-FZ 